\title{
SPECTROSCOPIC SIMULATION OF DIFFUSE INTERSTELLAR LINES AND A LABORATORY MODEL FOR INTERSTELLAR CHEMICAL SYNTHESIS
}

\author{
F. M. JOHNSON \\ Dept. of Physics, California State University, Fullerton, Calif. 92634, U.S.A. \\ and \\ D. T. BAILEY and P. A. WEGNER \\ Dept. of Chemistry, California State University, Fullerton, Calif. 92634, U.S.A.
}

\begin{abstract}
The interstellar existence of dipyridyl magnesium tetrabenzporphin (I) is supported by the spectroscopic coincidence of laboratory generated and astronomically observed diffuse interstellar lines. A potential route for the synthesis of $I$ in space from molecules which exist or are expected to exist there will be discussed.

Initially, we wish to review some of the spectroscopic evidence for the identification of the diffuse interstellar lines as being due to dipyridyl magnesium tetrabenzporphin (I). Laboratory spectra (Johnson, 1972, a, b) of this molecule taken at $77{ }^{\circ} \mathrm{K}$ (matrix isolation, Skpol'skii technique) resulted in the spectra shown in Table I. Also shown in this table is data taken by Sevchenko et al. (1967) corraborating some of our spectra.
\end{abstract}

TABLE I

Laboratory spectra of dipyridyl magnesium tetrabenzporphin (I) compared with corresponding diffuse interstellar astronomical data

\begin{tabular}{|c|c|c|c|c|}
\hline \multirow{2}{*}{$\begin{array}{l}\text { Laboratory data } \\
\text { MgTBP } \\
\text { Johnson } \\
(1972 a, b)\end{array}$} & \multirow[b]{2}{*}{ width $(\AA)$} & \multirow[b]{2}{*}{$\begin{array}{l}\text { MgTBP } \\
\text { Sevchenko } \\
\text { et al. (1967) }\end{array}$} & \multicolumn{2}{|c|}{ Astronomical data } \\
\hline & & & wavelength $(\AA)$ & width $(\AA)$ \\
\hline $6663 \AA$ & $1-2$ & & 6661 & 1 \\
\hline $6633 \mathrm{vw}$ & & & & \\
\hline $6628 w$ & & $6623 \AA$ & & \\
\hline 6614 & $1-2$ & & 6614 & 1 \\
\hline f $6610 \mathrm{vw}$ & & 6570 & & \\
\hline \multicolumn{5}{|l|}{ f $6334 \mathrm{vw}$} \\
\hline & & 6404 & & \\
\hline & & 6377 & 6376 & 2 \\
\hline \multicolumn{5}{|l|}{ f $6289 \mathrm{~s}$} \\
\hline f $6284 \mathrm{~s}$ & $1-2$ & 6282 & 6284 & 4 \\
\hline abs 6174 & 14 (total) & & 6175 & 30 \\
\hline \multirow{2}{*}{\multicolumn{5}{|c|}{$\begin{array}{c}\text { abs } 4428 v s \\
6274^{\mathrm{b}}\end{array}$}} \\
\hline & & & & \\
\hline $6278^{\mathrm{b}}$ & & & & \\
\hline
\end{tabular}

$\mathrm{f}=$ fluorescence data.

" Herbig (private communication).

b Probable assignment: dihydrotetrabenzporphin. 


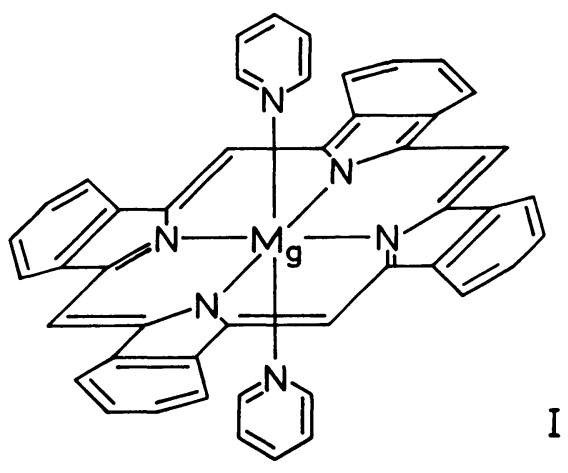

Fig. 1. The interstellar molecule $\chi\left(\mathrm{MgC}_{46} \mathrm{H}_{30} \mathrm{~N}_{6}\right)$.

Note the coincidence of the laboratory spectra with the astronomical data, in particular the strongest interstellar band at $4428 \AA$ coincides with the strongest laboratory generated band of $I$. There are now six coincidences to $\pm 2 \AA$ and correlation of line width to within a factor of two for all the identified laboratory and astronomical data. Additional corraboration for this identification is based on the infrared measurement of I, whereby IR absorption data of this molecule, characterizing some of the dominant vibrational modes, can be used to construct an energy level diagram which shows excellent coincidences with the observed astronomical spectroscopic data. Further more, all of the 25 diffuse interstellar lines, kindly obtained from Herbig (privatecommunication), fit to within $\pm 2 \mathrm{~cm}^{-1}$ of the laboratory observed vibrations of $\mathbf{I}$. The identification if $\mathbf{I}$ is in fact more reliable than that of a microwave molecule based on a single line coincidence. Two questions posed by the existence of $I$ are: (1) how is I produced in the interstellar medium and (2) why do most of the astronomically observed transitions arise from excited states? This paper gives a plausible stellar synthesis of I and gives a possible explanation for excited state transitions.

Microwave techniques (Rank et al., 1971; Snyder, 1972) have now identified a series of organic molecules containing acetylenic and cyano functional groups (Table II). Additionally, Table II contains some symmetric molecules, not observable by microwave spectroscopy, which in view of their close similarity to already identified

TABLE II

Structure of accepted interstellar acetylene and cyano derivatives

$\mathrm{H}-\mathrm{C} \equiv \mathrm{C}-\mathrm{CH}_{3}$ methylacetylene $\mathbf{H}-\mathbf{C} \equiv \mathbf{N}$ hydrogen cyanide
$\mathrm{H}-\mathrm{C} \equiv \mathrm{C}-\mathrm{C} \equiv \mathrm{N}$ cyanoacetylene $\cdot \mathrm{C} \equiv \mathrm{N}$ cyanide radical

Likely symmetrical interstellar acetylene and cyano derivatives

\begin{tabular}{lll}
\hline $\mathrm{H}-\mathrm{C} \equiv \mathrm{C}-\mathrm{H}$ & $\mathrm{N} \equiv \mathrm{C}-\mathrm{C} \equiv \mathrm{N}$ & $\begin{array}{l}\mathrm{H}-\mathrm{C} \equiv \mathrm{C}-\mathrm{C} \equiv \mathrm{C}-\mathrm{H} \\
\text { diacetylene }\end{array}$ \\
cyanogen
\end{tabular}


molecules almost certainly should also exist in space. These postulated molecules are acetylene, cyanogen and diacetylene. Although not observable by microwave techniques these molecules should be seen in the infrared and UV region of the spectrum (possibly in an excited state, in analogy with $\mathbf{I}$ and some of the 'microwave molecules').

A synthetic route to I requires a brief review of some known chemistry of acetylenic and cyano group functions with emphasis on the well known cyclization reactions of these groups. Acetylene and some substituted acetylenes undergo a facile condensation reaction to form benzene derivatives (Equation (1)). This is a very general type of reaction (Bird, 1967) with little restriction on the nature of the $\mathbf{R}$ group.<smiles>[R]C=C=C[R]</smiles>

The reaction occurs in the temperature range of 500 to $700{ }^{\circ} \mathrm{K}$ or catalytically at lower temperatures. Using the eight molecules in Table II (now identified in space or likely to be found there) and the cyclization chemistry just emphasized we would predict the following large molecules susceptable to interstellar synthesis: benzene (II), toluene (III), benzonitrile (IV) and phenylacetylene (V). This list is of course not exhaustive but is exemplary of the type of benzene derivatives which should be searched for in astronomical studies. Another class of molecules susceptable to 'interstellar' synthesis are pyridine derivatives. Again using molecules from Table II and the cyclization reaction of Equation (1), we suggest the possible 'interstellar' existence of pyridine (VI), 2-methylpyridine (VII), 2-cyanopyridine (VIII), and 2-ethynylpyridine (IX).

$$
2 \mathrm{H}-\mathrm{C} \equiv \mathrm{C}-\mathrm{H} \longrightarrow \mathrm{H} \equiv \mathrm{C}-\mathrm{H}+\mathrm{H}-\mathrm{C} \equiv \mathrm{C}-\mathrm{CH}_{3} \longrightarrow \mathrm{II}
$$


$2 \mathrm{H}-\mathrm{C} \equiv \mathrm{C}-\mathrm{H}+\mathrm{H}-\mathrm{C} \equiv \mathrm{N} \longrightarrow \mathrm{C}_{\mathrm{N}}$

II

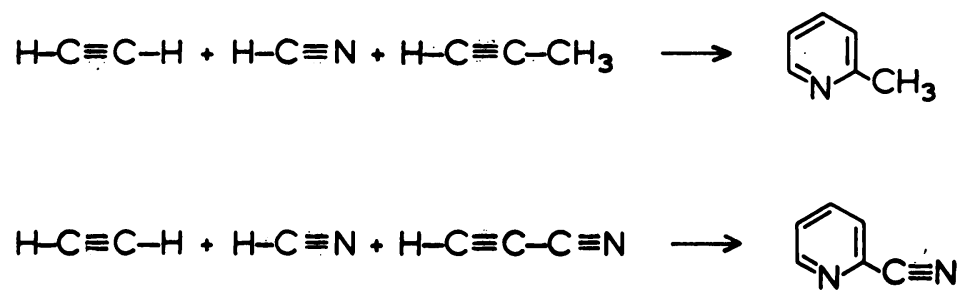

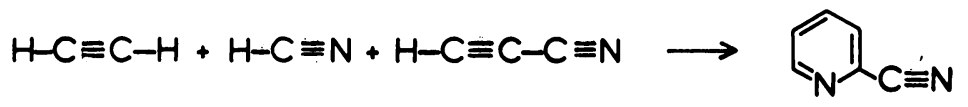

ZII

VIII

$$
H-C \equiv C-H+H-C \equiv N+H-C \equiv C-C \equiv C-H \longrightarrow C_{N} \equiv C-H
$$

Using the condensation reaction shown in Equation (1) and three molecules from Table II, $o$-cyanophenylacetylene $(\mathbf{X})$ can be prepared (Equation (10)). This molecule is isoelectronic to phthalonitrile (XI)<smiles>C#Cc1ccccc1C#N</smiles>

which undergoes a well known condensation reaction with a variety of metals to yield metallo-phthalocyanine (XII) (Cotton and Wilkinson, 1972) (Equation (11)). Assuming a similar condensation of $\mathbf{X}$, magnesium tetrabenzporphin (XIII) could be synthesized

4
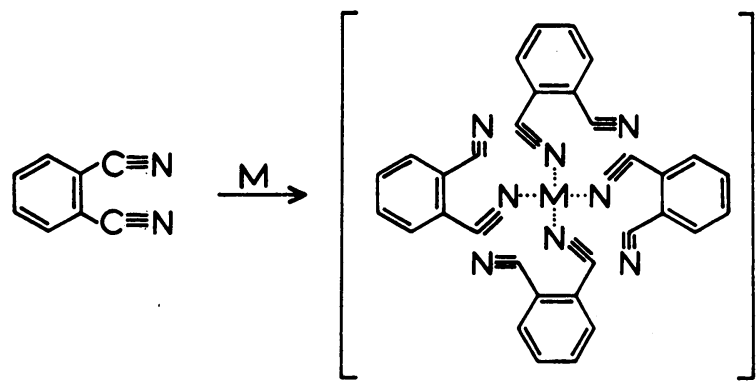

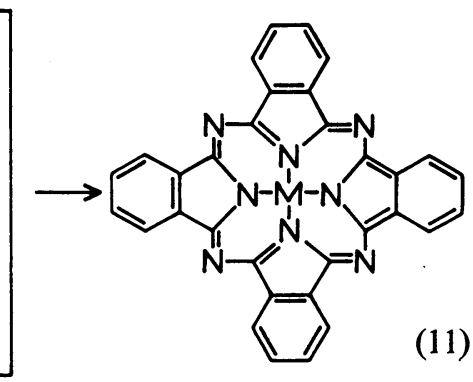


(Equation (12)). Addition of pyridine above and below the ring

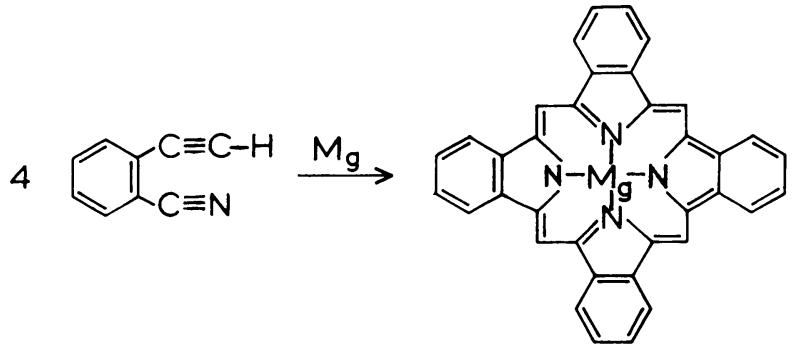

XIII

would generate $\mathbb{I}$. The only step of the entire sequence for the synthesis of $\mathbb{I}$ which is not based on completely known chemical reactions is the final condensation of $\mathbf{X}$ to form magnesium tetrabenzporphin. We are presently examining this reaction.

The stability of I rests on its conjugated bonds and the stability of the benzenes attached to the pyrrole structures. The resonance energy (Longo et al., 1970) of such a molecule is in excess of $400{ }^{\circ} \mathrm{K}$ calories.

Finally, the reason why a large number of observed diffuse interstellar lines arise from excited states may be due to the astronomical observation of these molecules under conditions of formation (Johnson, 1972b) whereby the molecule is in an excited state upon completion of the exothermic cyclization process. A similar situation is observed in other chemical reactions, i.e. thermo-luminescence arising from the gas phase synthesis of a molecule (Klemperer, 1971). We therefore believe (1) a synthetic pathway for the formation of $I$ in space exists and (2) that this pathway embodys an exothermic condensation reaction explaining the observation that I exists in excited vibrational states.

\section{Acknowledgements}

We wish to acknowledge the support of this work by NASA Grant NGR 05-071-002.

\section{References}

Bird, W. C.: 1967, Transition Metal Intermediates in Organic Synthesis, Logos Press, London.

Cotton, F. A. and Wilkinson, G.: 1972, Advanced Inorganic Chemistry, 3rd ed., John Wiley \& Sons, New York, p. 626.

Herbig, G. H.: private communication.

Johnson, F. M.: 1972a, Ann. N.Y. Acad. Sci. 187, 186.

Johnson, F. M.: 1972b, Mém. Soc. Roy. Sci. Liège, 6th Ser. III, 391.

Klemperer, W.: 1971, in C. de Jager (ed.), Highlights of Astronomy, p. 421.

Longo, F. R., Finarelli, J. D., Schmalzbach, E., and Adler, A. D.: 1970, J. Phys. Chem. 74, 3296.

Sevchenko, A. N., Solov'ev, K., Gradyushko, A., and Shkirman, S.: 1967, Soviet Phys.-Dokl. 11 (7), 587-590.

Rank, D. M., Townes, C. H., and Welch, W. J.: 1971, Science 174, 1083. 